\title{
Visual estimation of blood loss versus quantification of blood loss after vaginal birth using an innovative drape: a prospective study
}

\author{
Nalini Mishra, Suman Dhruw*, Ishan Mishra, Abha Daharwal
}

Department of Obstetrics and Gynecology, Pt. Jawahar Lal Nehru Memorial Medical College, Raipur, Chhattisgarh, India

Received: 29 October 2020

Revised: 10 December 2020

Accepted: 11 December 2020

\section{*Correspondence:}

Dr. Suman Dhruw,

E-mail: dhruwsuman477@gmail.com

Copyright: (C) the author(s), publisher and licensee Medip Academy. This is an open-access article distributed under the terms of the Creative Commons Attribution Non-Commercial License, which permits unrestricted non-commercial use, distribution, and reproduction in any medium, provided the original work is properly cited.

\begin{abstract}
Background: This study was done to compare the accuracy of visual estimation of blood loss (EBL) and quantitative assessment of blood loss (QBL, sum of volumetric and gravimetric assessment) against a reference standard i.e. calculated QBL (C-QBL) and also with each other after vaginal birth.

Methods: Prospective observational cohort study conducted at Pt. JNM medical College Raipur, Chhattisgarh, India and involved 101 low risk women after vaginal birth. Women were allocated alternately to EBL or QBL group (volumetric component of measured blood loss was done with an innovative low cost drape prepared with a plastic apron at the point of care. Gravimetric component was measured by weight difference of the mops and pads before and after use). C-QBL was calculated for each case with a standard formula. Main outcome measure was comparing the correlation coefficient of EBL and QBL each with C-QBL.

Results: The mean blood loss in 51 women of EBL group and 50 women of QBL group was $275.29 \mathrm{ml}$ and $380 \mathrm{ml}$ respectively. Pearson's correlation coefficient (r) of EBL with C-QBL was 0.4984 (weak correlation) compared to that of QBL with C-QBL ( $\mathrm{r}=0.9093$, strong positive correlation). The error of underestimation by EBL compared to QBL was $28 \%$ (mean $=104.71 \mathrm{ml} \mathrm{p}<0.0001)$. The relative risk $(\mathrm{RR})$ of underestimating blood loss of $>500 \mathrm{ml}$ by EBL method was 5 (95\% CI .605-41.3).

Conclusions: Visual EBL should be replaced with QBL for measurement of postpartum blood loss. Using innovative under-buttock low cost drape greatly helps in routine QBL.
\end{abstract}

Keywords: Blood collection drape, Calculated quantitative assessment of blood loss, Estimated blood loss, Innovative drape, Postpartum blood loss, Quantitative assessment of blood loss

\section{INTRODUCTION}

Postpartum haemorrhage (PPH) is the major contributor to maternal mortality and morbidity in the developing countries. ${ }^{1,2}$ Around $54-93 \%$ of maternal deaths owing to PPH may be preventable. Given that nearly $40 \%$ of PPH occurs in low risk women, every parturient is at risk. ${ }^{3}$ Most deaths due to PPH involve delayed diagnosis caused by underestimation of blood loss resulting into delayed management. ${ }^{4}$ An ideal method for estimation of blood loss at delivery should be accurate but very accurate methods like dye dilution technique, change in peripartum haemoglobin, red blood cell labelling and photospectrometry involve blood extraction or injection of some substance and therefore are not practical or affordable particularly in low and middle income countries (LMICs). The recently reported use of artificial intelligence (AI) namely Triton too is not feasible in these settings. 5,6

The pragmatic methods of assessing postpartum bleeding are visual estimation of blood loss (EBL) and quantitative assessment of blood loss (QBL) which includes direct collection (volumetric) added to that measured by 
weighing (gravimetric). EBL still remains the most commonly employed method in clinical practice in spite of various reports of gross underestimation of the actual blood loss by virtue of it being a subjective assessment. ${ }^{7-}$ 11 The QBL is reported to be more accurate and reproducible and is now an integral component of obstetric haemorrhage bundles. ${ }^{12-22}$

For women delivering vaginally, use of an under-buttock drape with graduated markings is much preferred and correlates well with photospectrometry values too. ${ }^{23}$

Most of the direct assessment methods have not been validated against an accurate method of blood loss like change in peripartum haemoglobin or haematocrit which is a reference standard and can detect all kinds of blood loss. ${ }^{24}$ Recent Cochrane review of methods for blood loss estimation after vaginal birth found the evidence to be insufficient as the trials included in the review did not report on their diagnostic accuracy along with some important outcomes particularly the clinical and maternal outcomes like postpartum anaemia, severe morbidity or infections. $^{25}$

The present study was conducted with an objective to assess the accuracy of visual estimation of blood loss (EBL) and that of QBL which is the combination of volumetric (using an innovative low cost drape) and gravimetric methods (weighted blood loss) against a standardized quantification method i.e. calculated QBL (C-QBL) and compare the two in order to generate evidence for a cost effective but accurate method of assessing blood loss after vaginal delivery.

\section{METHODS}

Present prospective observational non randomized cohort study was conducted in the government medical college and associated hospital of central India from November 2018 to June 2020 after obtaining clearance from the institutional ethical committee.

Low risk gravid women admitted in the labor room having single live fetus presenting by vertex, after 28 completed weeks of pregnancy and expecting vaginal delivery were recruited in the study. They have been approached when they entered into the active phase of labor and after obtaining informed consent, were subjected to thorough history taking, general and obstetric examination and reviewing of antenatal record.

Women having less than $8 \mathrm{gm}$ of haemoglobin, grandmultipara, post term, PROM, intrauterine death of fetus, multiple pregnancy, malpresentation, secondary $\mathrm{PPH}$, high risk pregnancy with medical disorders like PE, heart disease, coagulation disorders, on medications like aspirin or anticoagulant drugs, chronic malaria, sickle cell disease, diabetes, obstetric complication e.g. previous uterine surgeries (LSCS, myomectomy) with pregnancy, polyhydramnios, macrosomia, women under epidural analgesia, history of PPH in previous delivery, pregnancy with liomyoma uteri and women receiving blood transfusion during the study period were excluded from the study.

All women were monitored closely; findings were recorded in the partograph. Episiotomy was given if needed. The blood loss was quantified by methods given below in alternate cases:

\section{QBL group}

Volumetric estimation in calibrated drape was added to gravimetric blood loss. For this a blood collection drape (CG Drape) was prepared at the point of care as described (Figure 1). ${ }^{26}$ For the present study, the calibrations were done at every $100 \mathrm{ml}$ till $500 \mathrm{ml}$ and then at $1,1.5$ and 2 litres. The gravimetric assessment was done by weighing the dressing pads with an electronic scale before and after being used to wipe blood during episiotomy repair, difference of each gram was taken as one ml. Blood loss was measured for at least one hour but if bleeding continued after one hour, until active bleeding has stopped. At the time of shifting the woman from labour room to wards, she was provided with pre-weighed standard perineal pads. The number of pads used by the woman during the ensuing 24 hours was weighed and the difference was added to above measured direct plus gravimetric volume to derive the final sum of QBL.

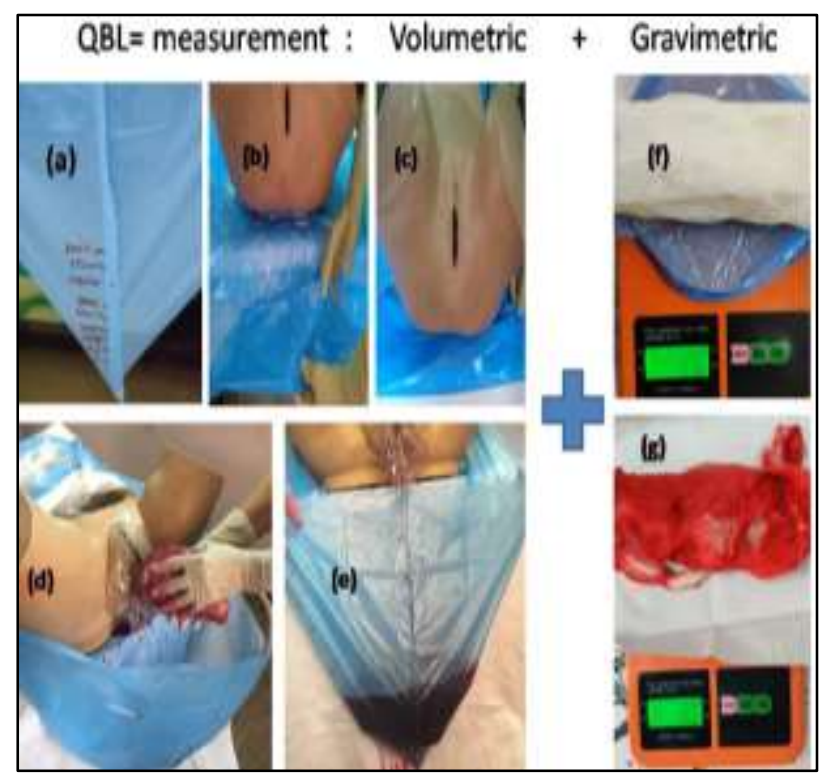

Figure 1: Quantitative assessment of blood loss done by direct estimation by CG drape + gravimetric assessment. (a) Calibrations on CG Drape; (b) and (c) Folding the conical collecting pouch under woman's buttocks before delivery; (d) and (e) collecting cone unfolded after delivery and blood loss measured directly in drape to measure volumetric component of QBL; (f) and (g) Weighing pads before and after use to measure gravimetric component of QBL. 


\section{EBL group}

Just after delivery and cord clamping, visual assessment of blood loss was made with the help of pictorial blood loss assessment method after holding a briefing session for all residents showing them the clinical reconstruction pictograms prepared with the help of unusable blood (obtained from institutional blood bank) by using precisely measured amounts to kidney tray, surgical sponges, perineal pad, drapes and sheets, on the delivery table and floor (Figure 2).

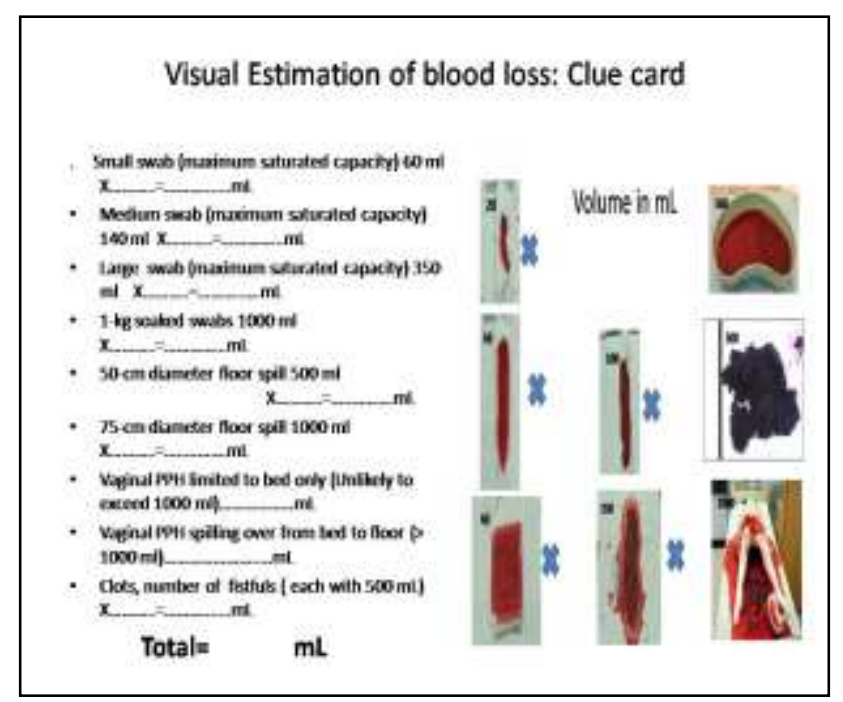

Figure 2: Clue card, for adding up all the items shown for visual Estimation of blood loss (EBL).

The blood loss was measured for at least one hour or, if bleeding continues after one hour, until active bleeding has stopped. The number of pads used by the woman during the ensuing 24 hours were also inspected and the estimated volume was added to above measured volume in order to derive the final sum of VBL.

\section{In both the groups}

10 IU of oxytocin was given intramuscularly within one minute of birth as part of active management of third stage of labour (AMTSL). Time of delivery and weight of the baby, interval between incision and repair was noted. Vital signs were noted in partograph before delivery and in the case records after delivery.

In case the blood loss perceived to exceed $500 \mathrm{ml}$ in either group, immediate intervention for PPH started including intravenous fluids, bladder emptying, examination of placenta and treating the cause. All the details were recorded.

Haemoglobin was estimated at the time of recruitment as well as 24 hours after delivery.
All women were followed up till the time of discharge.

\section{The reference standard}

Calculated QBL (C-QBL) was derived using the formula: $(0.75 \times\{[$ maternal height (inches) $\times 50]+[$ maternal weight in pounds $\times 25]\} \times[$ pre delivery HCT- post delivery HCT) / pre delivery HCT]. ${ }^{27}$

\section{Primary outcome}

Comparing correlation coefficient of visual estimation of blood loss (EBL) and quantification of blood loss (QBL using blood collection drape) with a reference standard of calculated quantification of blood loss (C-QBL) as well as with each other for the magnitude of discrepancy between the two methods in low risk gravid women after vaginal delivery.

\section{Secondary outcome}

To compare VBL and QBL for: mean blood loss, incidence of blood loss greater than $500 \mathrm{ml}$, pre- and post delivery change in haemoglobin concentration with number of women having $>10 \%$ decline or postpartum anaemia (haemoglobin $\%<9 \mathrm{gm} \%$ ), need of intravenous fluids or therapeutic uterotonics and second line interventions for management of PPH or hysterectomy, serious maternal morbidity or mortality.

\section{Statistical analysis}

The data was collected in proforma, entered into Excel 2016 sheet and analysed with SPSS version 20. Student's unpaired $t$ test was used for analysis of continuous variables whereas the categorical variables were analyzed by Chi square test with $\mathrm{p}<0.05$ considered as significant. A linear regression analysis was done to estimate the reference standard (C-QBL) with EBL and QBL using Pearson's correlation coefficient. Relative risk of wrong estimation was calculated.

\section{RESULTS}

A total of 101 women were allocated for either of the two methods for assessment of blood loss after vaginal delivery. Out of these 51 were in EBL and 50 in QBL group respectively. The two groups were well-matched for demographic variables and labour outcomes (Table 1). No baby had birth asphyxia.

Blood loss estimation in the two groups after delivery at $100 \mathrm{ml}$ discrete categories is given in Table 2. The QBL group showed comparable mean blood loss against that of C-QBL across all categories whereas EBL group exhibited significant underestimation in $>500 \mathrm{ml}$ category. Relative risk (RR) of underestimating blood loss of $>500 \mathrm{ml}$ by EBL method was 5 (95\% CI $0.605-$ 41.3). 
Table 1: Epidemiological and labour variables in EBL versus QBL groups.

\begin{tabular}{|c|c|c|c|}
\hline Variables & $\begin{array}{l}\text { EBL group; mean } \pm \text { SD } \\
(\mathrm{N}=51)\end{array}$ & $\begin{array}{l}\text { QBL group; mean } \pm \text { SD } \\
(\mathrm{N}=50)\end{array}$ & $P$ value \\
\hline Maternal age (years) & $25.00 \pm 5.00$ & $25.00 \pm 7.25$ & $0.916(\mathrm{NS})$ \\
\hline Parity & $2.0(39.2 \%)$ & $2.3(46.0 \%)$ & $0.491(\mathrm{NS})$ \\
\hline Gestational age (weeks) & $38.00 \pm 1.00$ & $38.50 \pm 2.00$ & $0.605(\mathrm{NS})$ \\
\hline Weight (in pounds) & $59.96 \pm 6.17$ & $57.46 \pm 7.76$ & $0.077(\mathrm{NS})$ \\
\hline Height ( in inches) & $151.55 \pm 3.83$ & $150.26 \pm 4.15$ & $0.108(\mathrm{NS})$ \\
\hline BMI & $26.08 \pm 2.28$ & $25.41 \pm 2.97$ & $0.205(\mathrm{NS})$ \\
\hline Rural residence & $40(78.4 \%)$ & $41(82.0 \%)$ & $0.653(\mathrm{NS})$ \\
\hline Duration of $1^{\text {st }}$ stage of labour (hours) & $12.00 \pm 11.00$ & $12.30 \pm 14.00$ & $0.530(\mathrm{NS})$ \\
\hline Duration of $2^{\text {nd }}$ stage of labour (minutes) & $24.00 \pm 12.00$ & $24.00 \pm 18.00$ & $0.411(\mathrm{NS})$ \\
\hline Duration of $3^{\text {rd }}$ stage of labour (minutes) & $17.00 \pm 5.00$ & $18.00 \pm 5.00$ & $0.233(\mathrm{NS})$ \\
\hline Birth weight (kg) & $2.90 \pm 0.40$ & $2.90 \pm 0.27$ & $0.784(\mathrm{NS})$ \\
\hline Episiotomy- delivery interval (minutes) & $7.00 \pm 0.30$ & $7.00 \pm 0.40$ & $0.310(\mathrm{NS})$ \\
\hline Delivery- repair interval (minutes) & $3.00 \pm 2.00$ & $3.00 \pm 2.00$ & $0.256(\mathrm{NS})$ \\
\hline Episiotomy- repair interval (minutes) & $22(41.2 \%)$ & $26(54.0 \%)$ & $0.197(\mathrm{NS})$ \\
\hline Pre delivery Hb (gm\%) & $10.88 \pm 1.02$ & $10.58 \pm 0.96$ & $0.135(\mathrm{NS})$ \\
\hline Post delivery Hb (gm\%) & $10.80 \pm 1.13$ & $10.56 \pm 0.88$ & $0.257(\mathrm{NS})$ \\
\hline Change in $\mathrm{Hb} \%$ & $0.696 \pm 0.572$ & $0.66 \pm 0.357$ & NS \\
\hline
\end{tabular}

Table 2: Comparison of blood loss at $100 \mathrm{ml}$ discrete categories.

\begin{tabular}{|c|c|c|c|c|}
\hline & EBL group & & QBL group & \\
\hline $\begin{array}{l}\text { Blood loss range } \\
(\mathrm{ml})\end{array}$ & $\begin{array}{l}\text { EBL }(n=51) ; N(\%) \\
\text { mean }\end{array}$ & $\begin{array}{l}\text { C-QBL for EBL group } \\
(\mathrm{n}=51) ; \mathrm{N}(\%) \text { mean }\end{array}$ & $\begin{array}{l}\text { QBL }(n=50) ; N(\%) \\
\text { mean }\end{array}$ & $\begin{array}{l}\text { C-QBL for QBL group } \\
(\mathrm{n}=50) ; \mathrm{N}(\%) \text { mean }\end{array}$ \\
\hline $100-200$ & $13(25.4 \%) 193.87 \mathrm{ml}$ & $13(25.4 \%) 136.09 \mathrm{ml}$ & $01(2 \%) 190 \mathrm{ml}$ & $08(16 \%) 162.50 \mathrm{ml}$ \\
\hline 200-300 & $22(43.1 \%) 242.72 \mathrm{ml}$ & $13(25.4 \%) 277.19 \mathrm{ml}$ & $15(30 \%) 258.66 \mathrm{ml}$ & $17(34 \%) 273.06 \mathrm{ml}$ \\
\hline $300-400$ & $12(23.5 \%) 356.66 \mathrm{ml}$ & $13(25.4 \%) 345.00 \mathrm{ml}$ & $15(30 \%) 347 \mathrm{ml}$ & $08(16 \%) 338.37 \mathrm{ml}$ \\
\hline $400-500$ & (03 (5.8\%) $440 \mathrm{ml}$ & $07(13.7 \%) 452.02 \mathrm{ml}$ & $16(32 \%) 452.02 \mathrm{ml}$ & $13(26 \%) 457.56 \mathrm{ml}$ \\
\hline$>500 \mathrm{PPH}$ & $01(1.9 \%) 580 \mathrm{ml}$ & $05(9.8 \%) 768.52 \mathrm{ml}$ & $03(06 \%) 773.33 \mathrm{ml}$ & 04 (8\%) $686.28 \mathrm{ml}$ \\
\hline $\begin{array}{l}\text { No. of PPH } \\
\text { identified by the } \\
\text { method }\end{array}$ & 01 out of $5=20 \%$ & & 03 out of $04=75 \%$ & \\
\hline $\begin{array}{l}\text { Relative risk of } \\
\text { missing blood loss } \\
>500 \mathrm{ml} \\
\text { EBL versus QBL }\end{array}$ & \multicolumn{4}{|c|}{$\mathrm{RR}=5 \quad(95 \% \mathrm{CI} \quad .605-41.31)$} \\
\hline
\end{tabular}

There were $07(13.7 \%)$ cases in EBL and $6(12 \%)$ in QBL group with peripartum haemoglobin decline of $>10 \%$ and the average drop in haemoglobin was 13.198 and $13.552 \%$ respectively. In the rest of women this change was only $\pm 5 \%$. The overall number of women with postpartum haemoglobin $\%$ of $<9 \mathrm{gm} \%$ was 06 (about 12\%) in each group.

The mean blood loss at one hour of delivery in the EBL group was $197.2 \pm 94 \mathrm{ml}$ compared to QBL group with $297.2 \pm 138.28 \mathrm{ml}$ and the difference was significant statistically ( $\mathrm{p}<0001,95 \%$ CI 75.63-132). The scatter plots of the mean blood loss shows wider variation in the EBL group when compared with the QBL group (Figure $3)$.

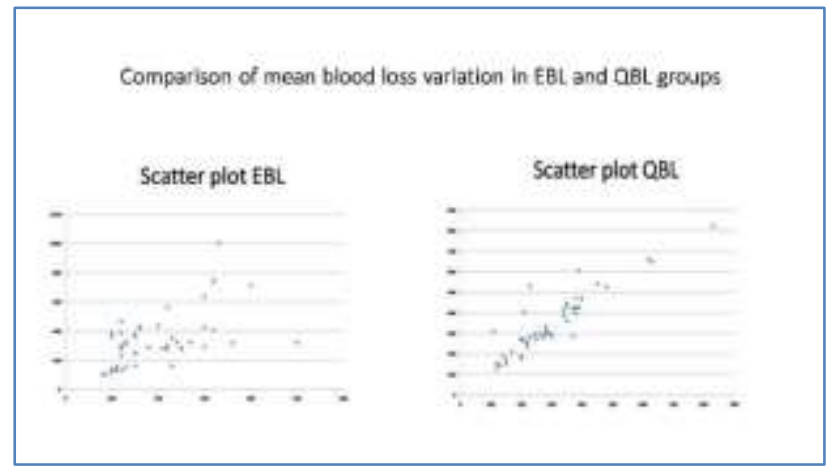

Figure 3: Scattered plot: comparison of mean blood loss in EBL and QBL group. 
Table 3: Comparison of EBL and QBL groups for mean blood loss and Pearson's correlation coefficient with C-QBL.

\begin{tabular}{|c|c|c|c|c|c|c|c|c|}
\hline Variable & EBL group $(\mathbf{n = 5 1})$ & & & QBL group ( & $\mathrm{n}=\mathbf{5 0})$ & & & $\begin{array}{l}\text { EBL versus } \\
\text { QBL } \\
\text { effect size }\end{array}$ \\
\hline & Cases (EBL) C-QBL & $\begin{array}{l}\text { Pearson's } \\
\text { correlation } \\
\text { coefficient } \\
\mathbf{r}\end{array}$ & $\mathbf{P}$ & $\begin{array}{l}\text { Cases } \\
(\mathrm{QBL})\end{array}$ & C-QBL & $\begin{array}{l}\text { Pearson's } \\
\text { correlation } \\
\text { coefficient } \\
\mathbf{r}\end{array}$ & $\mathbf{P}$ & \multirow[t]{2}{*}{$\begin{array}{l}\text { Difference } \\
=28 \% \\
p<0.0001\end{array}$} \\
\hline $\begin{array}{l}\text { Blood loss } \\
(\mathrm{ml}) \\
\text { mean } \pm \text { SD }\end{array}$ & $275.29 \pm 89.82 \quad 330.84 \pm 185.631$ & 0.4984 & $\begin{array}{l}<0.05 \\
(\mathrm{~S})\end{array}$ & $380 \pm 137.310$ & $346.85 \pm 147.265$ & 0.9039 & $\begin{array}{l}0.27 \\
\text { (NS) }\end{array}$ & \\
\hline
\end{tabular}

Table 3 shows the cumulative mean blood loss in EBL group (275.29 $\pm 89.82 \mathrm{ml})$ compared to reference standard for the same $(\mathrm{C}-\mathrm{QBL}=330.84 \pm 184.63)$ and the difference is significant statistically. The mean blood loss was $380 \pm 137.3 \mathrm{ml}$ in QBL group and when compared to CQBL for the same group, there was no significant difference.

The Pearson correlation coefficient for EBL and C-QBL was 0.4984 showing weak correlation whereas for QBL and C-QBL was 0.9039 demonstrating a strong positive correlation and greater accuracy for QBL group. The QBL was significantly higher (28\%) than EBL (380 ml and $275.29 \mathrm{ml}$, respectively with a mean difference of $104.71 \mathrm{ml}(\mathrm{p}<0.001)$.

After being shifted from labour room, average number of pads used by the parturient were three over the next 24 hours and the corresponding volume was added to that measured at the end of one hour giving the cumulative blood loss. None of the women had abnormal blood loss after being shifted to ward.

All women were followed till the time of discharge, the mean duration of stay was 48 hours. There was no incidence of any features suggestive of infection, hysterectomy, organ failure, admission to ICU/HDU or maternal mortality.

\section{DISCUSSION}

"Seeing is not believing" stands true in the present study where the accuracy of EBL compared with reference standard ' $\mathrm{C}-\mathrm{QBL}$ ' was found to correlate poorly $(\mathrm{r}=0.4984)$ in contrast to $\mathrm{QBL}$ with a positive correlation coefficient $(r=0.9039)$ with C-QBL, establishing the superiority of the QBL over EBL.

The error of underestimation by EBL compared to QBL was around $28 \%$ (mean blood loss difference $=104.71 \mathrm{ml}$ $\mathrm{p}<0.0001$ ) and is in accordance with other studies showing underestimation by visual estimation ranging from 31-50\%., ${ }^{7,12,13}$ The strong correlation of QBL with the reference standard concurs well with many studies using an objective standard reference involving the change of haemoglobin. ${ }^{12,14,15,28,29}$

For assessment of the volumetric component of QBL, a calibrated drape is a practical, reliable and user friendly modality. ${ }^{13,23,26}$ The latest ACOG committee opinion for QBL in obstetric haemorrhage has also emphasized the value of calibrated drape or weighing over and above the visual estimation. ${ }^{3}$ Cochrane review (2018) could not discern whether direct estimation by calibrated drapes truly overestimated blood loss because of doubtful discrimination between blood and amniotic fluid. ${ }^{25}$ To avoid such mixing, the drape used in the present study showed the distinct advantage of being made of a soft plastic so that the collection pouch could be kept folded under the buttocks before delivery (Figure 1) and swiftly unfolded afterward in order to avert error due to amniotic fluid.

Though the difference between EBL and QBL appears small in terms of $\mathrm{ml}$ of blood lost but when this percentage $(28 \%)$ is extrapolated to higher volumes, is likely to miss the diagnosis of PPH resulting in delay of treatment. When practice of QBL is done routinely, it requires only minutes to perform. The major hassle of availability of the drape has been solved in the present study where it is prepared at the point of care only and is very cost effective (approximately Rs. 15 each), does not require manufacturing and distribution. It is also ecofriendly because it is decontaminated after use and is then disposed of as medical waste or incinerated. ${ }^{26}$ The gravimetric component becomes much smaller when the drape is used to estimate the major part (about 80-90\%) of total blood lost. This makes assessment less time and resource consuming and thereby enabling regular practice of QBL.

QBL is reported to accurately detect postpartum haemorrhage and when used as an integral component of obstetric haemorrhage bundles, has been found to reduce maternal morbidity significantly and rationalize resources. ${ }^{7,13,14,18,22,28,30,31}$

Taking into consideration the fact that clinical variables were comparable in both the groups, the expected blood 
loss could have not been significantly different but it was found to be so. The incidence of PPH in QBL: EBL group was 3:1 and is in agreement with another study. ${ }^{13}$ All cases of PPH responded to initial treatment and none lost $>1000 \mathrm{ml}$ and therefore no significant change in the vital parameters was observed but the scenario may not always be favourable and missing out $66 \%$ PPH by EBL may be detrimental to already anaemic women of LMICs. The argument of improving EBL using various standardization visual tools have not been consistent and the effect did not last long. ${ }^{9}$

Limitation is the small size of the study, however in view of very strict recruitment criteria and using a reference standard (C-QBL) calculated and compared for each case, the accuracy of results is worthwhile as a pilot project.

\section{CONCLUSION}

To summarize the present study, the correlation between QBL and reference standard had been significantly better than EBL. QBL using a local calibrated drape is easy, cost effective, pragmatic and should be a routine clinical practice to ensure early and timely detection of exact amount of blood loss. A habit of doing appropriate assessment of blood loss can help in early detection of PPH so that corrective measures can be implemented in time in these women who are already anaemic. It can go a long way to prevent maternal mortality and morbidity.

\section{Funding: No funding sources}

Conflict of interest: None declared

Ethical approval: The study was approved by the Institutional Ethics Committee

\section{REFERENCES}

1. Roth GA, Abate D, Abate KH, Abay SM, Abbafati $\mathrm{C}$, Abbasi N, et al. Global, regional, and national age-sex-specific mortality for 282 causes of death in 195 countries and territories, 1980-2017: a systematic analysis for the Global Burden of Disease Study 2017. Lancet. 2018;392(10159):1736-88.

2. Nathan LM. An overview of obstetric hemorrhage. Semin Perinatol. 2019;43:2-4.

3. American College of Obstetricians and Gynecologists. Quantitative blood loss in obstetric hemorrhage. ACOG Committee Opinion No. 794. Obstet Gynecol. 2019;134:e150-6.

4. Seacrist MJ, VanOtterloo LR, Morton CH, Main EK. Quality improvement opportunities identified through case review of pregnancy-related deaths from obstetric hemorrhage. J Obstet Gynecol Neonat Nurs. 2019;48:288-99.

5. Saoud F, Stone A, Nutter A, Hankins GD, Saade GR, Saad AF. Validation of a new method to assess estimated blood loss in the obstetric population undergoing cesarean delivery. Am J Obstet Gynecol. 2019;221(3):267.e1-6.
6. Rubenstein A, Tully G, Thurer R. Accurate assessment of blood loss during cesarean delivery improves estimate of postoperative hemoglobin [17B]. Obstet Gynecol. 2018;131:23S-4S.

7. Lyndon A, McNulty J, Wal BV, Gabel K, Huwe V, Main E. Cumulative quantitative assessment of blood loss. California Maternal Quality Care Collaborative (CMQCC) obstetric hemorrhage toolkit Version 2.0.

8. Mahadalkar P, Podder L, Memchoubi JD, Pottal S, Devi S, Gadade M. Accuracy of visual estimation of blood loss by simulated learning package. Int J Nurs Res Pract. 2015;2(1):20-3.

9. Hancock A, Weeks AD, Lavender DT. Is accurate and reliable blood loss estimation the "crucial step" in early detection of postpartum haemorrhage: an integrative review of the literature. BMC Pregnanc Childbirth. 2015;15:230.

10. Andrikopoulou M, D'Alton ME. Postpartum hemorrhage: early identification challenges. Semin Perinatol. 2019;43:11-7.

11. Natrella M, Di Naro E, Loverro M, BenshalomTirosh N, Trojano G, Tirosh D, et al. The more you lose the more you miss: accuracy of postpartum blood loss visual estimation. A systematic review of the literature. J Matern Fetal Neonat Med. 2018;31:106-15.

12. Lilley G, Burkett-St-Laurent D, Precious E, Bruynseels D, Kaye A, Sanders J, et al. Measurement of blood loss during postpartum haemorrhage. Int $\mathbf{J}$ Obstet Anesth. 2015;24(1):8-14.

13. Lertbunnaphong $\mathrm{T}$, Lapthanapat $\mathrm{N}$, Leetheeragul J, Hakularb P, Ownon A. Postpartum blood loss: visual estimation versus objective quantification with a novel birthing drape. Singapore Med J. 2016;57(6):325-8.

14. Rubenstein AF, Zamudio S, Al-Khan A, Douglas C, Sledge S, Tully G, et al. Clinical experience with the implementation of accurate measurement of blood loss during caesarean delivery: influences on hemorrhage recognition and allogeneic transfusion. Am J Perinatol. 2018;35:655-9.

15. Powell E, James D, Collis R, Collins PW, Pallmann $\mathrm{P}$, Bell S. Introduction of standardized, cumulative quantitative measurement of blood loss into routine maternity care. J Matern Fet Neonat Med. 2020:1-7.

16. Katz D, Wang R, O'Neil L, Gerber C, Lankford A, Rogers $\mathrm{T}$, et al. The association between the introduction of quantitative assessment of postpartum blood loss and institutional changes in clinical practice: an observational study. Int J Obstet Anesth. 2020;42:4-10.

17. Goffman D, Ananth CV, Fleischer A, D'Alton M, Lavery JA, Smiley R, et al. The New York State Safe Motherhood Initiative: early impact of obstetric hemorrhage bundle implementation. Safe Motherhood Initiative Obstetric Hemorrhage Work Group. Am J Perinatol. 2019;36(13):1344-50.

18. Main EK, Cape V, Abreo A, Vasher J, Woods A, Carpenter A, et al. Reduction of severe maternal morbidity from hemorrhage using a state perinatal 
quality collaborative. Am J Obstet Gynecol. 2017;216:298.e1-11.

19. Main EK, Goffman D, Scavone BM, Low LK, Bingham D, Fontaine PL, et al. National partnership for maternal safety consensus bundle on obstetric hemorrhage. J Midwife Women Health. 2015;60(4):458-64.

20. Goffman D, Moroz L. Introduction. Semin Perinatol 2019; 43(1): 1 .

21. Bingham D, Scheich B, Bateman BT. Structure, process, and outcome data of AWHONN's postpartum hemorrhage quality improvement project. J Obstet Gynecol Neonatal Nurs. 2018;47:707-18.

22. Shields LE, Wiesner S, Fulton J, Pelletreau B. Comprehensive maternal hemorrhage protocols reduce the use of blood products and improve patient safety. Am J Obstet Gynecol. 2015;212:272-80.

23. Patel A, Goudar SS, Geller SE, Kodkany BS, Edlavitch SA, Wagh K, et al. Drape estimation vs. visual assessment for estimating postpartum hemorrhage. Int J Gynecol Obstet. 2006;93(3):220-4.

24. Atukunda EC, Mugyenyi GR, Obua C, Atuhumuza EB, Musinguzi N, Tornes YF, et al. Measuring postpartum haemorrhage in low-resource settings: the diagnostic validity of weighed blood loss versus quantitative changes in hemoglobin. PLoS One. 2016;11(4).

25. Diaz V, Abalos E, Carroli G. Methods for blood loss estimation after vaginal birth. Cochrane Database Systemat Rev. 2018;9:CD010980.

26. Mishra N, Baghel M, Gupta A, Shrivastava S, Chandrawanshi $\mathrm{H}$. Use of Innovative low cost drape for assessment of blood loss during delivery: a report. J South Asian Federation Obstet Gynaecol. 2019;11(1):30-4.

27. Wasley SR, Holmes HJ, Kauffman RP, Gouldy D. Estimating blood loss: which is superior. Am J Obstet Gynaecol. 2020;222(1):S345-6.
28. Kahr MK, Brun R, Zimmermann R, Franke D, Haslinger C. Validation of a quantitative system for real-time measurement of postpartum blood loss. Arch Gynecol Obstet. 2018;298(6):1071-7.

29. Hire MG, Lange EM, Vaidyanathan M, Armour KL, Toledo P. Effect of quantification of blood loss on activation of a postpartum hemorrhage protocol and use of resources. J Obstet Gynecol Neonat Nurs. 2020;49(2):137-43.

30. Einerson BD, Miller ES, Grobman WA. Does a postpartum hemorrhage patient safety program result in sustained changes in management and outcomes? Am J Obstet Gynecol. 2015;212:140-4.

31. Doctorvaladan SV, Jelks A, Hsieh E. Accuracy of blood loss measurement during cesarean delivery. AJP Rep. 2017;07(02):e93-100.

32. Coviello E, Iqbal S, Kawakita T, Chornock R, Cheney M, Desale S, et al. Effect of implementing quantitative blood loss assessment at the time of delivery. Am J Perinatol. 2019;36(13):1332-6.

33. Hamm RF, Wang E, Romanos A, O'Rourke K, Srinivas SK. Implementation of quantification of blood loss does not improve prediction of hemoglobin drop in deliveries with average blood loss. Am J Perinatol. 2018;35(02):134-9.

34. Mavrides E, Allard S, Chandraharan E, Collins P, Green L, Hunt BJ, et al. Prevention and management of postpartum haemorrhage. BJOG. 2016;124:e10649.

35. Fedoruk K. Seligman KM, Carvalho B, Butwick AJ. Assessing the association between blood loss and postoperative hemoglobin after cesarean delivery: a prospective study of 4 blood loss measurement modalities. Anesth Analg. 2019;128:926-32.

Cite this article as: Mishra N, Dhruw S, Mishra I, Daharwal A. Visual estimation of blood loss versus quantification of blood loss after vaginal birth using an innovative drape: a prospective study. Int J Reprod Contracept Obstet Gynecol 2021;10:268-74. 